\title{
0 Idealismo Crítico e o Sistema do Idealismo: um problema sem fundamento?
}

\author{
Paulo R. Licht dos Santos \\ Universidade Federal de São Carlos \\ licht@uol.com.br
}

resumo Como entender o "idealismo alemão"? Propõe-se aqui, a partir do choque entre algumas posições sobre a filosofia kantiana (sobretudo em Schopenhauer e em Schelling), antes do que uma resposta, articular alguns problemas em torno do "idealismo alemão", procurando pensar, assim, tanto a ambigüidade deste recorte como operador heurístico quanto a abertura possível para um campo de questões sobre a atividade filosófica e o seu (não) fundamento.

palavras-chave Kant; Schelling; Schopenhauer; idealismo crítico; sistema do idealismo

Não ofereceria o termo "idealismo alemão", apesar de sua utilidade para indicar certo parentesco entre alguns filósofos e temáticas, um recorte ambíguo na história da filosofia, de modo que mais parece abrir um campo de discussões infindáveis do que circunscrever um território onde questões, se não respondidas, poderiam ao menos ser levantadas, a exemplo, talvez, do campo da subjetividade, tido muitas vezes como o solo em que estaria fincada a alternância, na filosofia moderna, entre o eu puro e o eu empírico 2 ?

De fato, por um lado, o recorte identifica, sem mais, Fichte, Schelling e Hegel, de modo que não deixa de haver intérpretes ou filósofos que, ciosos da diferença entre os sistemas filosóficos, propõem afastar um ou outro da ilustre linhagem ${ }^{3}$. Por outro lado, as diferenças parecem tão acentuadas que não se sabe ao certo se os discípulos de Kant, Reinhold e Beck deveriam ser perfilados com os primeiros antikantianos, Schulze e 
Jacobi, e todos, por sua vez, contados entre Schlegel e Novalis ${ }^{4}$, sem falar de Schopenhauer, que, embora mencionado como membro da "nova corrente espiritual" (HARTMANN, 1983, p. 12-13), não raro é deixado de fora do álbum de família do idealismo alemão. Se é assim, por que não fazer com essa expressão o que o próprio Schopenhauer já antes aconselhara ao mundo erudito a propósito de palavra tão vaga e polissêmica como "pagão”: “(...) é necessário que as portas de saída lhe sejam mostradas; ela pode viajar para Inglaterra e fixar residência em Oxford" (SCHOPENHAUER, 1988, p. 143)? No entanto, como último recurso talvez ainda se poderia dizer: sejam quais forem as ambigüidades, parece sólido que o ponto de partida é a filosofia de Kant, tal como se pode ler, de resto, no texto conhecido como O mais antigo programa de sistema do idealismo alemão: "Kant (...) deu apenas um exemplo, sem nada esgotar" (In: BECKENKAMP, 2004, p. 204). Aliás, não é a incerteza quanto à autoria do Programa (atribuído pelos estudiosos ora a Schelling, ora a Hegel, ora a Hölderlin) o índice de que, sejam quais forem as ramificações posteriores, seria uma verdade manifesta que se radicam todas em Kant? É precisamente o que sugere Hegel em sua Ciência da Lógica: "a filosofia kantiana constitui a base e o ponto de partida da filosofia moderna e este mérito que é seu em nada é afectado pelo que a seu respeito se possa dizer" (cit. por SANTOS, 1994, p. 149)5.

Ora, de que Kant se trata? Que Kant está em jogo? Pois se já se afirmou com muito acerto que a filosofia crítica não nos traz outra verdade, apenas nos ensina a pensar de outra maneira, introduzindo uma "língua nova", também é certo que a filosofia crítica não se instaura num céu puramente azul, desprovido de todo pensamento e de toda linguagem. Ao contrário, a filosofia kantiana é lida, compreendida e mal-entendida segundo certas maneiras já vigentes de pensar e a partir de conceitos já antes formulados e diversamente empregados. Assim, Garve e a filosofia popular não enxergam nela senão a reafirmação antimetafísica, um tanto rebuscada, dos conhecidos limites da razão humana, nada mais, enfim, do que a recomendação do senso-comum para ficar no solo da sensação e do fenômeno; ou, inversamente, em virtude desses mesmos limites, é considerada pelo pastor e matemático Johann Schulz (que Kant irá depois converter em intérprete autorizado da Crítica; cf. a declaração pública de Kant contra Schlettwein, de 1797; KANT, 1902, XII, 362) uma abertura

doispontos, Curitiba, São Carlos, vol. 4, n. 1, p. 11-26, abril, 2007 
para as verdades reveladas e para os mistérios da religião cristã. Ou Kant, em razão dos ataques críticos à metafísica clássica, é visto por Mendelssonhn como o demolidor de tudo, o Alleszermalmer; ou então é acusado, pelo cético Schulze, de não fazer nada mais do que reeditar o antigo dogmatismo, por Kant sustentar, em plena contradição com as premissas da dedução transcendental, que há um ser exterior ao pensamento, a coisa em si, que seria a causa não sensível das representações sensíveis. Ou é tida por Jacobi, no calor da disputa sobre a filosofia de Espinosa e o estatuto da filosofia (a "Querela sobre o panteísmo"6), menos como inconsistente do que inconseqüente, em virtude de Kant situar a objetividade no interior da representação, sem, contudo, ousar desembaraçar-se da premissa de que há objetos exteriores à representação ${ }^{7}$. A filosofia crítica ora é considerada pelos leibnizianos uma ruptura com Leibniz, ora é assimilada a ele, aliás, pelo próprio Kant, que, em sua resposta a Eberhard, lhes censura a leitura literal dos textos do filósofo, a qual teria deixado escapar o que o próprio Leibniz quis dizer (KANT, 1902,VIII, 250). Uma passagem, note-se, que não passará despercebida a Fichte, da qual irá valer-se para abalizar sua chave de leitura da Crítica segundo o espírito, o que permitiria dissolver e superar as contradições dos kantianos ortodoxos que, presos à letra, teriam perdido a idéia do todo e, com ela, a unidade da obra (cf. FICHTE, 1971, p. 478-479). Eis, por fim, o idealismo legítimo e conseqüente, uma vez dissolvidas pelo espírito na apreensão do todo as contradições da letra de Kant? Talvez não; ao menos não, certamente, para o Kant intérprete de Kant, que, imiscuindo-se nas controvérsias em torno de sua filosofia, não só afirma que “a Crítica tem de ser efetivamente entendida segundo a letra”, mas também assegura, parecendo ter esquecido o que escrevera antes 8 , que nunca lhe teria passado pela cabeça "fornecer uma propedêutica para a filosofia transcendental, não o próprio sistema dessa filosofia (...)”, alegando que julgara "o todo acabado da filosofia pura na Crítica da razão pura como a melhor característica de sua verdade" (KANT, 1997, p. 59).

Ora, se a filosofia crítica, ao cair no domínio público, começa a multiplicar-se em questões e fragmentar-se em problemas, como ela poderia constituir "a base e o ponto de apóio" para um movimento que parece, de um lado e de outro, recusar-se a ser mapeado e sistematizado? Parece então que só nos resta mostrar ao "idealismo alemão" as portas de saída.

doispontos, Curitiba, São Carlos, vol. 4, n. 1, p. 11-26, abril, 2007 


\section{4}

Entretanto, antes de confortavelmente deixá-lo insular-se em algum nãolugar fora do mundo erudito, não deveríamos tirar proveito de sua própria fluidez para construir um espaço de relações, instaurando, ao mesmo tempo, uma abertura para pensar certas questões, como, talvez, a da prática (ou de certa prática) filosófica?

\section{$* * *$}

Ao propor um balanço geral da filosofia do século XVIII, recém encerrado, Reinhold, o divulgador de primeira hora da filosofia crítica, faz de Fichte não apenas o continuador de Kant, mas também, e, sobretudo, o filósofo plenamente conseqüente que, a partir de Kant, soube ir além de Kant:

Não há dúvida de que Fichte penetrou com mais profundidade do que

Kant no verdadeiro espírito do idealismo transcendental: (...), pois a

partir das duas filosofias críticas de Kant, a teórica e a prática, que se opõem em seu princípio tanto quanto por seu resultado, criou um edificio doutrinal único e integral (REINHOLD, K. L. 1986).

A avaliação de Reinhold sobre a inconsistência interna do idealismo kantiano e seu desenvolvimento mais conseqüente por Fichte não é, a certa altura do debate sobre a filosofia kantiana, opinião isolada. De fato, semelhante juízo também é proferido na resenha anônima sobre o Projeto de filosofia transcendental, de Buhle, escrito em 1798: “Kant é o primeiro mestre da filosofia transcendental, e Reinhold, o mais excelente divulgador da doutrina crítica; mas o primeiro filósofo transcendental mesmo é, indiscutivelmente, Fichte, que realizou o plano projetado pela Crítica e implementou, de modo sistemático, o idealismo transcendental indicado por Kant” (KANT, 1902, XIII p. 542-543)9 ${ }^{9}$. Portanto, não é de estranhar que seja como opinião corrente que Schelling se refira à falta de unidade da filosofia crítica: "Já se observou com freqüência que, no espírito de Kant, não é a idéia do todo de sua filosofia que teria precedido as suas partes, mas estas é que teriam precedido aquela, de modo que o todo teria se originado de maneira mais atômica do que orgânica" (SCHELLING, 1985, p. 15). Não há dúvida de que nesse texto, um breve 
porém belo panegírico publicado no ano da morte de Kant (1804), Schelling procura resguardar a grandeza e inteireza do filósofo: "Ainda que sua filosofia tenha surgido por partes, seu espírito mostra, porém, uma tendência natural e irrepreensível para a totalidade, que ele também atinge em sua esfera" (SCHELLING, 1985, p. 17; grifo no original).

Note-se que é a um duplo custo que Schelling preserva Kant. Em primeiro lugar, ao custo de atribuir uma cisão entre a obra e o espírito de seu autor: a obra teria nascido de partes, ainda que o espírito que a tenha formado tenha sido movido por uma tendência à totalidade. Em segundo lugar, ao custo de atribuir uma cisão entre essa própria tendência e a parcialidade do resultado efetivamente alcançado: pois se, como diz Schelling, a totalidade visada por Kant é atingida em sua esfera <in seiner Sphäre $>$, não estaria assumindo implicitamente que não é atingida na esfera integral do saber? No diagnóstico de Schelling, se entre a tendência e a realização cai a sombra, não é senão pela impotência inscrita na própria crítica, que, por seu caráter negativo e abstrato, estaria desprovida de um verdadeiro princípio que pudesse unificar e harmonizar o formal e o real, o abstrato e o efetivo, o universal e o singular. Aconteceria isso, primeiro, no uso teórico da razão: depois de separar o lado formal na crítica teórica da razão, Kant teria procurado, nos Primeiros princípios metafísicos da ciência da natureza, juntar o lado real, "mas sem alcançar, depois dessa separação, a unidade mais verdadeira dos princípios das duas partes, de sorte que sua filosofia pudesse tornar-se filosofia da natureza, sem que assim também pudesse desenvolver o universal até a sua perfeita harmonia com o singular" (SCHELLING, 1985, p. 18). Sem dúvida, a falta de unidade é, para Schelling, um problema do formalismo da crítica teórica, mas é também problema da crítica prática, pois também esta e sua presumida contrapartida efetiva, a Revolução Francesa10 " "tinham em comum o caráter simplesmente negativo e a solução insatisfatória do conflito entre a abstração e a realidade efetiva, conflito que não podia ser superado no primeiro caso na especulação e no outro na prática" (SCHELLING, 1985, p. 15). Daí que, exercida de modo meramente negativo, a tendência à totalidade de Kant só tenha podido realizar-se, por inteiro, no interior do limite traçado pela crítica: “... [Kant] traça precisamente o limite entre duas épocas da filosofia, das quais uma ele deu cabo para sempre e outra que preparou negativamente, ao restringir-se sabia-

doispontos, Curitiba, São Carlos, vol. 4, n. 1, p. 11-26, abril, 2007 
mente a seu fim, meramente crítico" (SCHELLING, 1985, p. 19). Assim, estabelecendo um corte na filosofia, a crítica superaria uma época, preparando ao mesmo tempo o terreno para ser superada.

Que imagem oferece Schelling da filosofia crítica? Uma que não difere muito da que é apresentada por Reinhold: a crítica, na superfície de sua letra, seria obra sem unidade orgânica, um mosaico composto atomicamente de partes; esse composto resultaria, decerto, da tendência ou impulso <Trieb $>$ do espírito de Kant para o todo, mas este todo só seria alcançado parcialmente no interior de uma crítica que seria, em si mesma, abstrata e negativa; porém, quando Kant pretende ir além do formalismo abstrato para unir o formal e o real, o universal e o singular, acabaria por revelar a incapacidade congênita da crítica, trazendo à luz do dia a ausência de uma "unidade verdadeira dos princípios de suas partes", tanto na filosofia teórica quanto na prática. Por isso, ir além da Kant não teria sido, para Schelling, senão um imperativo, cuja formulação, porém, já estaria contida de algum modo no próprio Kant: quanto ao "[...] fogo dos que foram adiante, não serviu senão para separar o ouro puro de sua filosofia dos ingredientes da época e apresentá-lo em seu puro brilho" (SCHELLING, 1985, p. 1). Mas se Schelling se aproxima de Reinhold na avaliação quanto à inconsistência da filosofia crítica, dele se afasta por não nomear Fichte entre "os que foram adiante". A se acreditar em Fichte, porém, são ele próprio e Schelling que possuem a chave do verdadeiro idealismo transcendental: "Estou de fato inteiramente convencido de que a filosofia kantiana é, se não deve ser tomada como nós a tomamos, um absurdo total (carta de Fichte a Schelling, de 20/09/1799)" (cit. por LICHT DOS SANTOS, 1997, p. 42). Seja como for, Hegel não hesita em conferir apenas a Fichte toda a honra de, por ter sido mais conseqüente do que o próprio Kant, ter alcançado a unidade ausente na filosofia kantiana: "o defeito da filosofia kantiana era sua inconsistência impensada, que subtraiu unidade especulativa ao sistema inteiro; esse defeito foi removido por Fichte (...). Sua filosofia (...) é, em especial, uma apresentação mais conseqüente da filosofia kantiana (...)" (HEGEL, 1993, p. 388).

Se também Schopenhauer vincula sua filosofia com a crítica de certa inconsistência do idealismo kantiano, como se configuraria essa crítica na distância mesma que procura tomar em relação aos demais sucessores de Kant? Se reconhece neste o marco de uma nova época na filosofia,

doispontos, Curitiba, São Carlos, vol. 4, n. 1, p. 11-26, abril, 2007 
Schopenhauer não deixa de torná-lo, ao menos em parte, o responsável imediato por novos erros: "Que as grandes realizações de Kant tivessem de ser acompanhadas de grandes erros, pode-se já calcular, apenas historicamente, a partir do fato de que, embora tenha realizado a maior revolução na filosofia (...), o resultado imediato de sua entrada em cena foi quase só negativo e não positivo (...), porque Kant não estabeleceu um sistema completo (...)" (SCHOPENHAUER, 1988, p. 93). Sem dúvida, com essas palavras Schopenhauer está longe de reconhecer algum parentesco com as doutrinas de Fichte ou dos demais que propuseram ir além da filosofia crítica. Ao contrário, Schopenhauer se faz passar pelo único sucessor imediato de Kant: “... não reconheço que tenha acontecido nela [na filosofia] o que quer que seja, entre ele e mim; por isso, ligo-me imediatamente a ele" (SCHOPENHAUER, 1988, p. 86). Assim, se Fichte teria ido além em alguma coisa, não seria senão na amplificação das imperfeições de Kant, abrindo caminho, então, para os erros maiores de Schelling e, sobretudo, de Hegel: "Se (...) a distinção entre fenômeno e coisa em si e, portanto, a doutrina da total diversidade do ideal e do real, é o traço fundamental da filosofia kantiana, a afirmação, que logo depois se apresentou, da identidade absoluta de ambas (...) não se apoiava senão na patacoada da intuição intelectual (...). Tornou-se o ponto de partida digno para o ainda mais grosseiro não-senso do desajeitado e pobre de espírito Hegel" (SCHOPENHAUER, 1988. p. 88).

Por um lado, os erros de Kant provêm do fato de não ter estabelecido um sistema completo; por outro, os sucessores de Kant, ao lançar-se na empreitada de ir além de Kant, não fizeram senão aprofundar-lhe os erros. Uma dupla injunção da qual se forma a tarefa que Schopenhauer atribui para si mesmo, enunciada, curiosamente, em termos muito próximos aos de Schelling: é preciso que "a doutrina de Kant seja esmerilhada do erro que adere a ela, para que a sua verdade brilhe tanto mais límpida e mantenha-se mais segura" (SCHOPENHAUER, 1988. p. 86). Que significa expurgar o erro do idealismo crítico? Nada senão radicalizar o idealismo, "a base" e "a alma" da filosofia kantiana ${ }^{11}$, reafirmando o "idealismo resoluto", diante do qual Kant teria recuado na segunda edição da Crítica da razão pura:

"Kant, embora não tivesse usado a fórmula 'não há objeto sem sujeito", explica, com a mesma decisão que Berkeley e eu, o mundo exterior,

doispontos, Curitiba, São Carlos, vol. 4, n. 1, p. 11-26, abril, 2007 
que se apresenta no espaço e no tempo, como mera representação do sujeito que o conhece (...). Porém, toda a passagem da página 348-349, onde Kant expõe seu idealismo resoluto com extrema clareza, foi por ele suprimida na segunda edição e, ao invés disso, introduzida uma grande quantidade de declarações conflitantes. Por isso, o texto da Crítica da razão pura, tal como circulou do ano de 1787 até o ano de 1838, tornou-se um texto desfigurado e pervertido, e a 'Crítica' tem sido um livro que se contradiz a si mesmo. Os detalhes sobre isso, bem como as conjecturas sobre as razões e fraquezas que teriam podido mover Kant no desfiguramento de sua obra imortal, eu as expus numa carta ao professor Rosenkranz [editor das obras de Kant]" (SCHOPENHAUER, 1988. p. 101).

É certo que, com essas linhas, Schopenhauer sugere que o recuo de Kant, com a conseqüente recaída no realismo dogmático, não apenas teria uma certidão de nascimento inconteste, mas também deixaria entrever as razões extrafilosóficas da manobra kantiana: conformar-se ao novo governo que sucedeu a Frederico, o Grande. É igualmente certo que, por explicar uma questão filosófica apelando para razões exteriores, Schopenhauer parece padecer do mesmo mal de que acusara Kant ${ }^{12}$. No entanto, à luz de outras passagens, a denúncia de Schopenhauer contra Kant, se não retirada nem mitigada, mostra-se mais alinhada ao diagnóstico que faz de um problema que, afetando a Crítica de lado a lado, ao menos daria espaço para aquele recuo e manobra. De que problema se trata? Em última análise, da ausência de uma distinção rigorosa entre sensibilidade e entendimento (um problema que, para Schopenhauer, marca as duas edições daquela obra): "O grande erro de Kant”, fonte de todas as dificuldades, teria sido não saber separar "rigorosamente as representações intuitivas dos conceitos" (SCHOPENHAUER, 1988, p. 103). Ora, sem essa distinção rigorosa, Kant teria criado um híbrido de ambos, manifestado em sua concepção de "objeto da experiência" (SCHOPENHAUER, 1988, p. 103), comprometendo, com isso, parte considerável da Estética (sobretudo a investigação da intuição empírica) e boa parte da Analítica ${ }^{13}$.

Comprometeria, em primeiro lugar, a Estética, pois Kant não poderia jamais dizer que, por meio da sensibilidade unicamente, é dada a repre- 
sentação de um objeto ${ }^{14}$, uma vez que, para representar um objeto, seria já necessária a aplicação do entendimento e das formas da intuição do espaço e do tempo às sensações, as únicas que, em rigor, seriam dadas ${ }^{15}$. Desse modo, sem ter para si uma distinção clara entre intuição e pensamento abstrato, Kant acabaria por "levar o pensar para dentro da intuição” (SCHOPENHAUER 1988. p. 105), não atentando ao fato de que só há representação e objeto quando o entendimento, por meio do conceito de causalidade (o único conceito a priori admitido por Schopenhauer), converte sensações dadas em uma representação, representação essa que se mostraria então, pela primeira vez, mas não antes, como objeto no espaço e no tempo. Mas, nesse mesmo lance, Kant comprometeria também a Analítica, pois, se a sensibilidade apresenta, por si só, um objeto dado, o entendimento não poderia fazer nada mais do que pensar um objeto individual (dado na intuição), perdendo, assim, o caráter da universalidade e da abstração que é sua característica essencial. Desta maneira, ao supor que o pensamento recebe coisas individuais como objeto, Kant cometeria o erro inverso do anterior, mas complementar, levando, agora, “o intuir para dentro do pensar" (SCHOPENHAUER, 1988, p. 105). Por fim, como desfecho dessa longa série de erros (enraizados, recorde-se, no próton pseudos que é não separar de modo rigoroso intuição e pensamento), Kant faria uma falsa demonstração da coisa em si, uma tese verdadeira, porém derivada de maneira incorreta com base no nexo causal. De que maneira? Ao admitir que a sensibilidade dá, por si mesma, sem concurso do entendimento, a representação de objetos como fenômenos, não restaria a Kant senão derivar essa representação dada de uma causa exterior a ela, a coisa em si, transgredindo assim o limite da experiência sensível, ao qual Kant havia confinado o uso legítimo da causalidade ${ }^{16}$.

Note-se que a crítica negativa de Schopenhauer traz consigo uma explicação positiva sobre a questão da representação do objeto. Com efeito, se a filosofia kantiana se enredaria em contradições é porque Kant não teria conseguido ver que a intuição é "efetivamente intelectual", intuição realizada "mediante a aplicação do conhecimento do nexo causal, que é a única função do entendimento" (SCHOPENHAUER, 1988, p. 108). No fundo, portanto, o grande erro de Kant, longe de resultar de razões circunstanciais ou exteriores, "consiste em não oferecer

doispontos, Curitiba, São Carlos, vol. 4, n. 1, p. 11-26, abril, 2007 
nenhuma teoria da gênese da intuição empírica, mas fazer dela algo dado, sem mais, identificando-a com a mera sensação dos sentidos" (SCHOPENHAUER, 1988, p. 109).

Assim se vê que, a seu modo e nos seus próprios termos, Schopenhauer, tal como Schelling, também acusa Kant de não resolver adequadamente o problema da relação entre o abstrato e o concreto. Sem dúvida, Schopenhauer parece opor-se Schelling, pois se este lamenta a ausência, na filosofia crítica, de uma "unidade mais verdadeira dos princípios" que possa harmonizar o universal e o singular, aquele deplora que Kant não tenha separado rigorosamente "as representações intuitivas dos conceitos". No entanto, o reverso da crítica de Schopenhauer também tem como contrapartida a exigência de uma unidade autêntica, da qual Kant, em razão de sua distinção imperfeita entre intuição e conceito, teria passado ao largo, obrigando-o a obtê-la à coup de force. Pois, na análise de Schopenhauer, a verdadeira unidade do objeto, sobre a qual o pensar se debruça para formar conceitos abstratos, "representações de representações", seria (diferentemente do que avalia ser o híbrido kantiano entre a intuição, representação singular do objeto, e conceito, representação universal de objetos) desde o início conferida por uma intuição empírica una ${ }^{17}$, uma intuição que é "efetivamente intelectual" (intuição esta que, note-se, é inteiramente diversa da intuição intelectual de Fichte $\left.{ }^{18}\right)$. Por isso, Schopenhauer exige do idealismo a gênese daquilo que Kant considera simplesmente dado, situando-se, a seu modo, numa perspectiva comum aos pós-kantianos (cf. ARANTES, 2000, p. 21).

Fecha-se, assim, um ciclo. De Reinhold a Schopenhauer, passando por Fichte, Schelling e Hegel, o idealismo kantiano aparece como duplamente imperfeito. Imperfeito, em primeiro lugar, porque, abandonado a si mesmo, não passaria de um agregado: "um absurdo total", diz Fichte; a Crítica, uma obra "que se contradiz a si mesma", escreve Schopenhauer, e a filosofia kantiana, consente Schelling, um todo que teria "se originado de maneira mais atômica do que orgânica". Assim, de todos os ângulos de que a filosofia crítica é considerada, não se reconhece nela nenhuma unidade sistemática; ou, caso se consinta possuir alguma, é atribuída a um "sistema de acomodação", a um artificio exterior do qual resultaria, quando muito, uma unidade arquitetônica, não, porém, uma verdadeira unidade orgânica ${ }^{19}$. Mas a filosofia crítica só seria imperfeita nessa 
primeira acepção porque Kant, assim julgam, teria ficado aquém do próprio espírito do seu idealismo, preso, portanto, a uma forma não inteiramente realizada. Por isso, para alguns desses filósofos (dois deles, Reinhold e Fichte, são por Kant chamados, ironicamente, "hipercríti$\cos ^{\prime 2} 20$ ) encontrar o princípio fundamental que dê unidade às partes não significaria senão sair da propedêutica crítica, desvendar a raiz comum entre sensibilidade e entendimento (para Kant, desconhecida e, talvez, incognoscível) e, finalmente, realizar o sistema do idealismo ou o idealismo resoluto. Em última análise, não significaria senão oferecer a gênese daquilo que, para Kant, é simplesmente assumido como dado, integrandoo, assim, num sistema unificante e totalizante.

Fecha-se um ciclo? $\mathrm{Na}$ verdade, apenas se delineou um lugar, de contigüidades e oposições, "sem nada esgotar". Não tanto porque haveria ainda outros filósofos que procuraram, de um modo ou de outro, superar Kant: como a crítica de Nietzsche voltada contra Kant, "o cristão capcioso" cujo prejuízo moral teria sido deixado intocado pela própria crítica; como Heidegger, que, centrando sua interpretação na imaginação, a raiz comum, tal como exposta na primeira edição da Crítica, insere Kant num horizonte ontológico; ou, por fim, como os neokantianos que, procurando salvar Kant de seus sucessores idealistas, propõem um retorno a Kant, com a intenção declarada de, atendo-se apenas ao espírito da filosofia crítica, "ultrapassar" a letra de Kant ${ }^{21}$.

Mas se não se fecha um ciclo é, sobretudo, porque permanecem em aberto, seja em relação à filosofia crítica, seja em relação aos seus continuadores, imediatos ou não, questões sobre o estatuto da filosofia, seu objeto e método de investigação e a relação entre teoria e prática. Não seria por isso, talvez, que a própria prática filosófica permanece o campo de batalhas que a crítica e a hipercrítica pretendiam apaziguar e superar de uma vez por todas 22 ? Seja como for, este campo, longe de ser um território já dado, como, de resto, parece sugerir a metáfora de Kant no Prefácio à segunda edição da Crítica $^{23}$, não é construído e instaurado no confronto mesmo entre posições que, não sendo asseguradas por completo nem podendo estender-se as mãos em perpétua unidade, formam-se e redesenham-se no próprio conflito e, desse modo, não podem jamais se esgotar numa forma acabada?

doispontos, Curitiba, São Carlos, vol. 4, n. 1, p. 11-26, abril, 2007 
${ }^{1}$ Agradeço aos primeiros leitores da versão inicial deste texto, Thelma Lessa da Fonseca e Maria Lúcia Cacciola; e a Vinicius de Figueiredo, cujas justas observações procurei aqui levar em consideração.

2 Em princípio, também se pode duvidar, se não da pertinência, ao menos da exatidão do "conceito de subjetividade" como "operador hermenêutico" para demarcar o território da filosofia moderna; nesse sentido, cf. RIBEIRO DE MOURA 2001.

3 Sobre esse cenário e as referências aos intérpretes, cf. BONACCINI, 2003, p. 377-378.

4 Sobre esse cenário, cf. BONACCINI, 2003, p. 387-388.

5 Cf. tb. Hartmann: "O que reúne pensadores do idealismo alemão num grupo homogéneo, a despeito das oposições e pontos de discussão conscientes, é, em primeiro lugar, a posição do problema comum. O ponto de partida para todos eles é a filosofia kantiana (...)" (HARTMANN 1983, p. 9).

${ }^{6}$ Sobre a querela do panteísmo e seus desdobramentos, cf. BUENO e FIGUEIREDO, 2005.

7 Cf. Jacobi: “(...) o defensor do idealismo transcendental deve muito simplesmente abandonar esse pressuposto e, provavelmente, nem sequer considerar que é verossímil a existência de coisas que, no entendimento transcendental, nos seriam exteriores (...). O idealismo transcendental tem, portanto, de possuir a coragem de defender o mais forte idealismo que jamais foi ensinado e não deve mesmo recear a acusação de egoísmo especulativo" (JACOBI 1992, p. 109).

8 Cf., por exemplo, o que Kant diz, referindo-se à própria Crítica da razão pura: "De minha parte, não posso doravante meter-me em controvérsias, embora atente cuidadosamente a todas as sugestões, seja de inimigos, para utilizá-las, de acordo com esta propedêutica, na futura execução do sistema" (KANT, 1987, XLIII; itálico meu). Cf. tb. KANT , 1987, B 869.

9 Essa resenha, que pedia a Kant uma posição pública quanto a essa questão, levou-o a publicar, em 1799, a Declaração sobre a Doutrina-da-Ciência de Fichte (cf. LICHT DOS SANTOS, 1997). A Declaração encontra-se traduzida em KANT, 1997 e, ao lado de outros textos de Kant e de pós-kantianos, em BECKENKAMP, 2004, p. 243-246.

10 O paralelismo entre a revolução copernicana de Kant e a Revolução Francesa não é, evidentemente, uma opinião isolada de Schelling, mas é tema recorrente nos pós-kantianos e em alguns leitores da obra de Kant. Note-se que, para Schelling, mais do que mero paralelismo, haveria em rigor uma completa homologia entre a revolução ideal na Alemanha e a revolução real na França: seria questão de "um e mesmo espírito", "uma íntima concordância e igualdade" (SCHELLING, 1985, p. 14, 15). Hegel, por sua vez, estende aos sucessores de Kant o que Schelling atribuíra apenas a este:"As filosofias de Kant, Fichte e Schelling. Nessas filosofias, a revolução está sedimentada e expressa na forma do pensamento (...). Na Alemanha, este princípio desdobrou-se em pensamento, espírito e conceito; na França, na efetividade." (HEGEL, 1993, p. 314). Cf. tb. Heine, que, no escrito publicado em 1833-34: Para a história da religião e da filosofia na Alemanha, procura explicar ao público francês o significado da Crítica da razão pura nos seguintes termos: "Com essa obra inicia-se na Alemanha uma revolução espiritual que apresenta singulares analogias com a revolução material ocorrida na França e deve ser considerada tão importante como aquela. Desenvolve-se segundo as mesmas fases e há entre ambas um notável paralelismo. Em ambos os lados do Reno, o mesmo corte

doispontos, Curitiba, São Carlos, vol. 4, n. 1, p. 11-26, abril, 2007 
com o passado, a mesma recusa em respeitar a tradição; tal como na França, assim na Alemanha cada pensamento tem de justificar-se; tal como cai na França a realeza, a cúpula da antiga ordem social, assim cai na Alemanha o deísmo, a cúpula do antigo regime do espírito" (cit. por SANTOS, 1994, p. 150).

11 “Tal conhecimento claro e tal exposição tranqüila e lúcida dessa índole onírica do mundo inteiro é, propriamente, a base de toda a filosofia kantiana, é sua alma e seu mérito máximo" (SCHOPENHAUER, 1988, p. 89).

12 Para semelhante interpretação da passagem de Schopenhauer aqui citada, cf. TORRES FILHO, 2004, p. 137-138.

13 Schopenhauer considera parte duradoura da Crítica apenas a Estética e a Analítica, atribuindo à Dialética um interesse meramente histórico e geográfico (cf. SCHOPENHAUER, 1988, p. 162).

14 Cf., por exemplo, Crítica da razão pura A 20/ B 34 (KANT 1902).

15 Semelhante observação já fora feita por J. S. Beck, em carta a Kant de 11 de novembro de 1791: "Penso que, na Estética Transcendental, de modo algum se pode explicar a intuição como a representação que se refere imediatamente a um objeto e se origina quando o objeto afeta a mente. Pois apenas na Lógica Transcendental pode ser mostrado como alcançamos a intuição objetiva" (cf. KANT 1902, XI, 338).

${ }^{16}$ Vê-se, assim, que a crítica de Schopenhauer ao recuo de Kant perante o "idealismo resoluto", embora explicitamente referida à segunda edição da Crítica, vale indiretamente também para a primeira edição, visto que, para Schopenhauer, é a inteira teoria kantiana do conhecimento que é, fundamentalmente, incorreta: "Mas sempre de novo se nos apresenta, na Critica da razão pura, aquele erro capital e fundamental de Kant (...): a total falta de distinção entre o conhecimento abstrato e discursivo e o intuitivo. É isto que difunde uma contínua obscuridade sobre a inteira teoria da faculdade de conhecer de Kant (...)" (SCHOPENHAUER 1988, p. 132).

17 Uma vez que a intuição é intelectual, “(...) a realidade empírica, portanto, a experiência, já está dada na própria intuição” (SCHOPENHAUER, 1988, p. 108).

18 Sobre a intuição intelectual em Fichte e em Schopenhauer, bem como a relação que possui com a questão da unidade orgânica, cf. KOßLER 2007.

19 Sobre a adoção em filosofia, por Fichte e por Schopenhauer, de um ideal de sistema orgânico decorrente da crítica ao formalismo da arquitetônica kantiana cf. KOßLER 2007.

20 Cf. carta de Kant a Tieftrunk de 13-10-1797 (KANT 1902, XII, p. 307).

21 É o que dizem Dufour e Servois: "É notável que a fidelidade ao kantismo conduza necessariamente a ultrapassar Kant. A tese de Kant é insustentável”. "É, de resto, a razão pela qual os neokantianos sustentam sua fidelidade não à letra do kantismo, mas somente ao seu espírito, afirmando unanimemente que 'compreender Kant é ultrapassar Kant'" (DUFOUR e SERVOIS 2005, p. 162 e p. 163). Um cenário das diferentes interpretações e retomadas de Kant também é apresentado por Leonel R. dos Santos (cf. SANTOS, 1994, pp. 143-157).

doispontos, Curitiba, São Carlos, vol. 4, n. 1, p. 11-26, abril, 2007 
22 Cf. a Declaração de Kant: “(...) A filosofia crítica tem de se sentir convencida, por sua irresistível tendência para apaziguar a razão, de que (...) o sistema da Crítica, assentando-se em uma fundação assegurada por completo, está firme para sempre e também é, para todas as épocas futuras, indispensável para os fins supremos da humanidade" (KANT, 1997, p. 60). Cf. o Mais antigo programa de sistema do idealismo alemão: "Assim, finalmente esclarecidos e não esclarecidos têm de estender-se dar a mão (...). Então se estenderá entre nós uma perpétua unidade" (ROSENZWEIG, in: BECKENKAMP, J. 2004, p. 206; trad. ligeiramente modificada).

23 A metafisica “(...) é, antes, um campo de batalha [Kampfplatz], que parece estar destinado, na verdade, a exercitar as forças no combate simulado e sobre o qual nenhum combatente ainda conseguiu conquistar para si o menor lugar [Platz] e fundar, com sua vitória, uma posse duradoura" (KANT, 1987, XV; trad. modificada).

\section{Referências bibliográficas}

ARANTES, P. E. 2000. Hegel: a ordem do tempo. São Paulo:

Hucitec/Polis.

BECKENKAMP, J. 2004. Entre Kant e Hegel. Porto Alegre: EDIPUCRS.

BONACCINI, J. A. 2003. Kant e o problema da coisa em si no idealismo alemão. Rio de Janeiro/Natal: Relume Dumrará/UFRN.

BUENO V. e FIGUEIREDO V. (orgs.) 2005. “A querela do Panteísmo", in: O que nos faz pensar, vol. 19. Rio de Janeiro: PUCRJ, pp. 5-180.

DUFOUR E. e SERVOIS J. 2005. "Le statut de l'espace esthétique dans la philosophie kantienne“. In: Kant-Studien, Berlin, Heft 2, pp. 161-181.

FICHTE, J. 1971. Zweite Einleitung in die Wissenschaftslehre. In: Fichtes Werke, I. Berlin: Walter de Gruyter.

HARTMANN, N. 1983. A filosofia do idealismo alemão, segunda ed. Trad. José Gonçalves Beto. Lisboa: Fundação Calouste Gulbenkian.

HEGEL, G. W. F. 1993. Vorlesung über die Geschichte der Philosophie, in: Werke, 20. Frankfurt am Main: Suhrkamp. 
JACOBI, F. H. 1992. Excertos de Über den transzendentalen Idealismus (Sobre o idealismo transcendental). Trad. Leopoldina Almeida. In: A Recepção da Crítica da Razão Pura. Lisboa: Fundação Gulbenkian. KANT, I. 1902 em diante. Gesammelte Schriften, vol. Ed. Königlich Preussischen Akademie der Wissenschaften. G. Reimer (Walter de Gruyter): Berlin.

1987. Crítica da razão pura, vol. 1. Trad.Valério

Rohden e Udo Baldur Moosbuger. Coleção Os Pensadores, São Paulo: Nova Cultural.

1997. Declaração sobre a Doutrina da Ciência de Fichte.

Trad. Paulo R. Licht dos Santos. In: Cadernos de filosofia alemã, ${ }^{\circ} 2$. São Paulo: USP, pp. 57-60.

KOßLER, M. 2007. “A única intuição - o único pensamento”. Trad. Paulo R. Licht dos Santos. In: Dois pontos, volume 4, número 1.

LICHT DOS SANTOS, P. R. 1997. “Quem possui a filosofia?” In: Cadernos de filosofia alemã, $\mathrm{n}^{\circ}$ 2. São Paulo: USP, pp. 35-55.

REINHOLD, K. L. 1986. Élements d'un tableau de la philosophie au début du XIX siècle (extraits). Trad. do alemão de Bernard Gilson. In: G. W.

Hegel, La différence entre les systémes philosophiques de Fichte et de Schelling. Paris:Vrin.

RIBEIRO DE MOURA, C. A. 2001. "Cartesianismo e Fenomenologia: um exame de paternidade”. In: Racionalidade e Crise. São Paulo: Discurso Editorial e Editora da UFPR.

SANTOS, L. R. 1994. A razão sensível: estudos kantianos. Lisboa: Edições Colibri.

SCHELLING, F. W. J. 1985. Immanuel Kant (1804). Ausgewählte Schriften, vol. 3. Frankfurt am Main: Suhrkamp.

SCHOPENHAUER, A. 1988. Crítica da filosofia kantiana. Trad. Maria Lúcia. M. O. Cacciola. Coleção Os Pensadores, São Paulo: Nova Cultural. 
TORRES FILHO, R. R. 1975. O espírito e a letra: a crítica da imaginação pura em Fichte. São Paulo: Ática.

.2004. "Dogmatismo e antidogmatismo: Kant na sala de aula". In: Ensaios de Filosofia Ilustrada, nova. ed. São Paulo: Iluminuras. 